\title{
Postpartum changes in maternal blood lead concentrations
}

\author{
Claire B Ernhart, Tom Greene
}

\begin{abstract}
Studies of lead concentrations in blood during pregnancy are of interest because of the possibility of adverse effects on the fetus. One report of a single case suggested that blood lead concentrations are raised during pregnancy. This is consistent with the hypothesis of a pregnancy induced mobilisation of lead from bone. Data presented herein, however, indicate that blood lead measures are appreciably lower at delivery than they are at six months post partum. Other factors including but not limited to transmission to the fetus, may be influencing lead concentrations during pregnancy.
\end{abstract}

The major concern about exposure to lead during pregnancy lies in the possibility of adverse effects on the fetus. ${ }^{1}$ Because the route of fetal exposure is through the placenta, pregnancy induced changes in maternal lead concentration will be a major determinant of fetal exposure at different stages of gestation.

Changes in lead concentrations in blood during pregnancy have been evaluated in several prospective studies. These changes are reported in terms of absolute values or in terms of correlations of lead concentrations with different times in pregnancy. Several reports describe a decrease in blood lead concentration through pregnancy. In one report, ${ }^{2}$ the decrease was greater than expected on the basis of increased plasma volume; in another ${ }^{3}$ a decrease, apparent in unadjusted data, was not found when the data were adjusted for haematocrit per cent (HCT\%). In a further study, ${ }^{4}$ HCT\% adjusted blood lead values showed no systemic changes with duration of pregnancy.

Increases in lead concentrations in blood might be expected as a result of hormonally induced mobilisation of lead from bone. ${ }^{56}$ Data from a single case ${ }^{7}$ indicated relatively constant blood lead concentra-

Case Western Reserve University and MetroHealth Medical Center, Cleveland, Ohio 44109, USA C B Ernhart, T Greene tions through the third trimester and the first seven months post partum followed then by a decline and halving of blood lead concentrations at 11 months post partum. These data have been described as indicating that blood lead concentrations may double during pregnancy as a result of transport from skeletal stores. If so, the risks for the fetus of a woman who has unusually high stores from past exposures may be increased. Because skeletal stores are difficult to measure, the possibility of risk to the fetus may be difficult to predict.

This issue would be most effectively considered by assembling a reasonably large number of women with known exposure histories and studying them before conception, during pregnancy, and for a lengthy postpartum (and postlactating) period. Given the difficult logistics of such a protocol, we may need to piece together studies of measures made during pregnancy that end with delivery and studies that contrast delivery and postpartum measures. We report here the results of a study relating maternal and cord blood lead concentrations at delivery and six months post partum.

\section{Subjects and samples}

The women participating had been recruited into a study of the use of alcohol in pregnancy at the time of their first visit for antenatal care at the clinics of a hospital that serves primarily indigent inner city

Table 1 Descriptive statistics for 307 women with blood lead data at delivery and at six months postpartum

\begin{tabular}{|c|c|c|}
\hline Variable & Mean or $\%$ & $S D$ \\
\hline \multicolumn{3}{|l|}{ Demographic data: } \\
\hline Race $(\%$ black $)$ & $30 \cdot 6$ & \\
\hline Maternal age (y) & $22 \cdot 2$ & $4 \cdot 4$ \\
\hline Maternal education (y) & $10 \cdot 6$ & 1.6 \\
\hline Parity & $1 \cdot 1$ & 1.2 \\
\hline \multicolumn{3}{|l|}{ Alcohol variables; } \\
\hline Mast $+(\%)$ & $45 \cdot 3$ & \\
\hline Alcohol/day ${ }^{\star}$ & 0.07 & $0 \cdot 19$ \\
\hline \multicolumn{3}{|l|}{ Smoking: } \\
\hline Smokers (\%) & & \\
\hline Cigarettes a day ${ }^{\star} \dagger$ & $14 \cdot 0$ & $12 \cdot 3$ \\
\hline Marijuana $(\%)^{\star}$ & $36 \cdot 5$ & \\
\hline Other illicit drugs $(\%)^{\star}$ & $9 \cdot 1$ & \\
\hline
\end{tabular}

^During pregnancy.

tIncludes non-smokers. 
Table 2 Means and standard deviations of blood lead concentration, HCT\%, and adjusted blood lead data for all subjects

\begin{tabular}{|c|c|c|c|c|c|}
\hline \multirow[b]{2}{*}{ Variable } & \multirow[b]{2}{*}{ No of subjects } & \multicolumn{2}{|c|}{ Arithmetic } & \multicolumn{2}{|c|}{ Geometric } \\
\hline & & Mean & $S D$ & Mean & $S D$ \\
\hline \multicolumn{6}{|c|}{ Blood lead concentration $(\mu \mathrm{g} / \mathrm{dl})$ : } \\
\hline $\begin{array}{l}\text { Delivery } \\
\text { Post partum }\end{array}$ & 185 & 6.5 & 1.9 & $\begin{array}{l}6 \cdot 2 \\
0.4\end{array}$ & 1.35 \\
\hline \multicolumn{6}{|l|}{ HCT $(\%)$ : } \\
\hline $\begin{array}{l}\text { Delivery } \\
\text { Post partum }\end{array}$ & 169 & $37 \cdot 1$ & $4 \cdot 1$ & & \\
\hline Post partum & 252 & $41 \cdot 3$ & $3 \cdot 0$ & & \\
\hline \multicolumn{6}{|c|}{ Adjusted blood lead concentration $(\mu \mathrm{g} / \mathrm{dl})^{\star}$ : } \\
\hline $\begin{array}{l}\text { Delivery } \\
\text { Post partum }\end{array}$ & $\begin{array}{l}169 \\
249\end{array}$ & $\begin{array}{l}6 \cdot 1 \\
8 \cdot 2\end{array}$ & $\begin{array}{l}1.8 \\
1.9\end{array}$ & $\begin{array}{l}5 \cdot 9 \\
8 \cdot 0\end{array}$ & $\begin{array}{l}1.35 \\
1.25\end{array}$ \\
\hline
\end{tabular}

*Adjusted blood lead values were computed by dividing whole blood lead concentrations by HCT\% and multiplying the result by 35 .

residents of an industrial city. By selection, half of the women were positive on the Michigan alcoholism screening test (MAST). Women who were MAST were selected to be matched to the MAST + women on a set of demographic and substance use indicators. Table 1 provides the descriptive statistics for the 307 women contributing data for the present analyses. Blood lead concentration was found to be related to maternal use of alcohol and cigarettes during pregnancy. ${ }^{8}$ Most of the women were not employed and none reported occupational exposure to lead.

\section{Methods}

At the time of delivery blood samples were obtained from 185 women whose children were identified for inclusion in a prospective study of risk factors in early child development. ${ }^{8}$ Failure to obtain blood samples from women followed through pregnancy whose infants were scheduled for longitudinal study was due primarily to limitations of staffing in the delivery suite. The perinatal exclusion criteria were related to consent and availability or, as in the case of preterm delivery (gestation $<37$ weeks), to probable confounding in the planned child development study. Details of selection have been previously published. $^{8}$

The mothers and children were visited in their homes at six months post partum. As well as the psychological testing indicated for the major purposes of the study, blood samples were drawn by a registered nurse from those mothers who consented and from their infants. Only $25 \%$ of these women breast fed their infants and only $8 \%$ continued past four months post partum.

Blood lead concentrations were determined by atomic absorption spectrophotometry. Details of the method and quality control procedures have been published previously. ${ }^{8}$

\section{Results}

Table 2 gives the means and standard deviations (SDs) of blood lead concentrations and HCT\% data for all subjects with these data. Blood lead data are provided in both arithmetic and geometric mode to facilitate comparisons with descriptions in other studies. As expected, HCT\% increased during the six month postpartum period. Because $\mathrm{HCT} \%$ may confound a blood lead determination. ${ }^{19}$ blood lead values were also computed with correction for HCT\%. Table 2 also gives the means and SDs for these adjusted blood lead concentrations.

It is apparent that both the unadjusted and adjusted mean blood lead concentrations are appreciably higher at the postpartum visit. Since the appropriate statistical tests must consider the correlation between measures at the two points in time, the sample was reduced to those cases with data at both times. The correlation between times was 0.50 for the 133 women with both measures.

Table 3 gives the means and SDs for the reduced sample. These did not differ notably from those for the full sample.

Table 3 Results of paired t tests contrasting results from delivery samples and samples collected six months post partum

\begin{tabular}{|c|c|c|c|c|c|c|}
\hline \multirow[b]{2}{*}{ Variable } & \multirow{2}{*}{$\begin{array}{l}\text { No } \\
\text { of subjects }\end{array}$} & \multicolumn{2}{|l|}{ Means } & \multirow[b]{2}{*}{$(95 \% C I) \dagger$} & \multirow[b]{2}{*}{ t value } & \multirow[b]{2}{*}{ p value } \\
\hline & & Delivery & Post partum & & & \\
\hline \multirow{3}{*}{$\begin{array}{l}\text { Blood lead } \\
\text { concentration }(\mu \mathrm{g} / \mathrm{dl})^{\star} \\
\text { HCT }(\%) \\
\text { Adjusted blood lead } \\
\text { concentration }(\mu \mathrm{g} / \mathrm{dl})^{\star}\end{array}$} & & & & & & \\
\hline & $\begin{array}{l}133 \\
119\end{array}$ & $\begin{array}{r}6 \cdot 7 \\
37 \cdot 0\end{array}$ & $\begin{array}{r}9.6 \\
41.6\end{array}$ & $\begin{array}{l}(2 \cdot 5-3 \cdot 3) \\
(3 \cdot 7-5 \cdot 5)\end{array}$ & $\begin{array}{l}15.9 \\
10.4\end{array}$ & $\begin{array}{l}<0.0001 \\
<0.0001\end{array}$ \\
\hline & 116 & $6 \cdot 2$ & $8 \cdot 0$ & $(1 \cdot 5-2 \cdot 2)$ & $8 \cdot 0$ & $<0.0001$ \\
\hline
\end{tabular}

^Arithmetic mean.

†CIs assess the mean differences between the postpartum and delivery values of the respective blood indices. 
Table 3 also gives the results of paired $t$ tests contrasting the measures at the two time points. As expected, the change in $\mathrm{HCT} \%$ was highly significant. The increase in blood lead concentration, whether adjusted for HCT\% or not, was also highly significant.

The increases in the lead concentrations during the six month postpartum period were pervasive throughout the cohort; the whole blood lead concentrations and $\mathrm{HCT} \%$ adjusted concentrations increased for $88.7 \%$ and $83.6 \%$ of the mothers respectively. Further unpaired $t$ tests indicated that the changes in the respective blood indices were not significantly related to race, smoking state, or to positivity on the MAST ( $p>0 \cdot 10$ in all cases). It should be noted, in particular, that the changes in lead concentrations found among the 64 MAST women were similar to those found for the full cohort; the mean increase in the $\mathrm{HCT} \%$ adjusted lead values was $1.6 \mu \mathrm{g} / \mathrm{dl}(\mathrm{t}=7.06, p<0.0001)$ in the MAST - women, compared with a mean increase of $1.8 \mu \mathrm{g} / \mathrm{dl}$ in the full cohort. (The screening programme used insured that the MAST - women were less likely to be influenced by exposure to alcohol than would be the case for a randomly selected sample.) Lead concentrations for the women who nursed their infants for four months or more were slightly higher than for the balance of the sample but the change in lead concentrations from delivery to six months post partum was not related significantly to breast feeding.

The distributions of both the whole blood lead concentrations and HCT\% adjusted lead concentrations showed a slight positive skewness. Consequently, the above analyses were repeated using log and square root transformed lead indices. In both analyses the results were similar to those reported above.

\section{Discussion}

The report of a single case ${ }^{7}$ of decreased postpartum blood lead concentration has been cited as supporting the hypothesis that mobilisation of lead from bone increases blood lead concentrations during gestation. The data from that case are not consistent with the findings of the present report.

Although our findings do not support the hypothesis of pregnancy induced mobilisation of lead from bone, they do not absolutely rule out this possibility. A similar study of women who might be expected to have high skeletal stores of lead through occupation or residence would be informative in this regard.

One explanation for lower blood lead concentrations in pregnancy is that the rise in plasma volume at this time might dilute the lead concentration. Alexander and Delves ${ }^{2}$ indicated that this might account for $10 \%$ of decreases in blood lead concen- tration during pregnancy. This, however, would account for only about half of the decrease they found. If we assume that our mean postpartum blood lead concentration is indicative of a baseline valuethat is, similar to the preconceptual or early pregnancy blood lead concentration, our data are consistent with theirs. We also find that the expected $10 \%$ difference is not sufficient to account for the observed discrepancy. We also evaluated the plasma dilution hypothesis by means of the HCT\% adjustment and found that this was not sufficient to account for the discrepancy between pregnancy and postpartum blood lead measures.

The decrease during pregnancy described by Alexander and Delves and the postpartum increase found in the present report may be due to transfer to fetal tissues and a subsequent return to equilibrium. Alternative possibilities include pregnancy induced metabolism and increased urinary excretion of lead during pregnancy. Hormonal changes due to the use of oral contraceptives (used by about half of this population) may also influence blood lead concentrations. We leave these possible explanations to be investigated by further research.

We thank Penny Erhard, BA, for her care in blood sample analysis. We are grateful to staff members, and to the women who participated. This research was supported in part by grant No LH-327 from the International Lead Zinc Research Organisation, Grant No 12-69 from the March of Dimes Birth Defects Foundation, and by the Perinatal Clinical Research Center of the MetroHealth Medical Center, US PHS Grant M01-RR00210.

Requests for reprints to: Dr Claire B Ernhart, Department of Psychiatry, MetroHealth Medical Center, 3395 Scranton Road, Cleveland, Ohio 44109, USA.

1 Ernhart CB. A critical review of low level prenatal lead exposure in the human: Effects on the fetus and newborn. Reproductive Toxicology 1991 (in press).

2 Alexander FW, Delves HT. Blood lead levels during pregnancy. International Journal of Occupational and Environmental Health 1981;48:35-9.

3 Shukla R, Bornschein RL, Dietrich KN, Buncher CR, Berger OG, Hammond PB, Succop PA. Fetal and infant lead exposure: Effects on growth in stature. Pediatrics 1989; 84:604-12.

4 McMichael AJ, Vimpani GV, Robertson EF, Baghurst PA, Clark PD. The Port Pirie cohort study: Maternal blood lead and pregnancy outcome. J Epidemiol Community Health 1986;40:18-25.

5 Buchet JP, Roels H, Hubermont G, Lauwerys R. Placental transfer of lead, mercury, cadmium, and carbon monoxide in women. Environ Res 1978;15:494-503.

6 Rosen JF. Metabolic and cellular effects of lead: A guide to low level lead toxicity in children. In: Mahaffey KR, ed. Dietary and environmental lead: Human health effects. Amsterdam: Elsevier, 1985.

7 Manton WI. Total contribution of airborne lead to blood lead. $\mathrm{Br} J$ of Ind Med 1985;42:168-72.

8 Ernhart CB, Wolf AW, Sokol RJ, Brittenham GM, Erhard P. Fetal lead exposure: Antenatal factors. Environ Res 1985; 38:54-66.

9 Ernhart CB, Brittenham G, Marler MR, Sokol RJ. Lead related birth defects: some methodological issues. In: Smith MA, Grant LD, Sors AI, eds. Lead exposure and child development, Dordrecht: Kluwer Academic Publishers, 1989.

Accepted 22 April 1991 